\title{
Managing Students' Diversity in Ethiopian Public Universities: Practices and Challenges
}

\author{
Mesfin Manaze ${ }^{1}$, Befekadu Zeleke ${ }^{2}$ \\ ${ }^{1}$ Assistant professor, Jigjiga University, Ethiopia \\ ${ }^{2}$ Associate professor, Addis Ababa University, Ethiopia \\ Correspondence: Mesfin Manaze, Assistant professor, Jigjiga University, Ethiopia.
}

Received: March 29, 2021

doi:10.11114/jets.v9i4.5217

\author{
Accepted: April 22, $2021 \quad$ Online Published: April 22, 2021 \\ URL: https://doi.org/10.11114/jets.v9i4.5217
}

\begin{abstract}
This study explored the practice and challenges of students' diversity management in Ethiopian public universities. A convergent parallel mixed method design was used to guide the study. To this end, stratified random and simple random sampling methods were used to select eight public universities and 458 participants of the study. Furthermore, purposive, availability, and snowball sampling methods were used to draw qualitative research participants. While a modified version of the campus climate for diversity instrument was used to collect the quantitative data, key informant interview and document review were employed as qualitative data gathering tools. Frequencies, means, an independent t-test, and one-way ANOVA were used to analyze the quantitative data while the qualitative data was analyzed thematically. Finally, the findings unveiled that the internal diversity-related policy practice, leadership commitment towards diversity promotion, diversity-related co-curricular activities, and curricular activities related to students' diversity management were rated as good. The study further disclosed a significant perception difference in leadership commitment towards diversity among students of different generations of universities, $F(3,454)=6.034, p=0.000)$. Moreover, the qualitative finding showed that the absence of well-planned strategies, the deficiency of the curriculum to respond to diversity-related issues, and lack of commitment of university leaders to promote diversity and act immediately during conflicts was mentioned as gaps in managing students' diversity. Finally, it was recommended that due attention should be given by MoSHE and respective public universities in diversifying the top leadership, academic staff, and student body by putting appropriate strategies in place.
\end{abstract}

Keywords: diversity, campus climate for diversity, sense of belonging, public universities

\section{Background}

Diversity management (DM) is the process or strategy of promoting the perception, acknowledgment, and implementation of diversity in organizations and institutions (Deshwal \& Choudhary, 2012). The promotion and implementation of diversity in organizations are to create an environment whereby all individuals can benefit and be successful. In this regard, Lumadi $(2008$, p.8) also defined DM as "the process of creating and maintaining a positive environment where the differences of all personnel are recognized, understood and valued so that all can achieve their full potential". From the definitions given above, one can understand that DM is concerned with the development and deployment of mechanisms that ensure acknowledgment and acceptance of differences between and among individuals or students in academic settings to be able to capitalize on the differences to create sustainable competitive advantages for all. In academic settings, an effective strategy in DM to create a campus environment that is inclusive and respecting of differences is making an assessment of the campus climate for diversity as it helps institutions to understand more about their students' diversity-related experiences (Jaeger \& Reverdy, 2013; Worthington, 2013) and create conditions to optimize engagement and desired outcomes or enhance the campus climate for diversity (Dawson, 2007; Hurtado, Milem, Clayton-Pedersen, \& Allen, 1998; 1999).

To make diversity a potential for students' and institutions' success, the campus climate for diversity should be enhanced through the application of different strategies of DM. According to researchers, these DM strategies include showing aspiration to enhance the campus climate for diversity (Brown, 2004), recognizing and including diversity in a university mission statement, policies, curriculum, and plans (Hurtado, 2005; 2007; Lumadi, 2008, Milem et al., 2005), enhancing of students' body composition (Antonio, 2001; Gurin et al., 2002; Hurtado, 2007; Skelly, 2004), and 
providing various opportunities for students that help them acquire knowledge about and experience diversity (Engberg, 2004; Umbach \& Kuh, 2006) which include providing diversity-related courses, workshops, and seminars that help students to know about diverse others, reduce prejudice and stereotypes, and challenge inequalities and injustices (Banks, 2001; Bell \& Griffin, 1997; Bennett, 1999; Engberg, 2004).

\section{Statement of the problem}

In Ethiopian public Universities, currently, it is a reality to find students from diverse backgrounds mainly due to two important reasons, recent relative higher expansion of higher education which enabled diverse student body to be enrolled in public universities and the admission and placement policy to higher education institutes (Abebaw, 2014). The ultimate goal of higher education institutions having such a diversified student body is to ensure positive learning outcomes of all students by properly addressing the needs of students of different backgrounds. The Ethiopian Higher Education Proclamation (FDRE, 2019), also stipulates that HEIs are expected to develop and disseminate the culture of respect, tolerance, and living together by rendering their service free from any form of discrimination on grounds of race, religion, sex, politics and other. In principle, the above statement in the higher education proclamation implies that higher education institutes are expected to have diversity-related institutional policies, rules and regulations, and management strategies to ensure the peaceful co-existence of their students.

Even though they have to play a vital role in addressing the diversity-related problems of the larger society, currently there are indications whereby Ethiopian public universities are not properly addressing the challenges of diversity even in their context. Some of the challenges that Ethiopian public universities are facing include several ethnic, religious, and gender-related conflicts between students which resulted in interruptions of their academic activity, injury, and have even claimed the lives of some students. For example, summarizing recent ethnic and other diversity-related conflicts at Ethiopian Public Universities, Ethiopia newspaper on November 11, 2018, summarized and reported that: there were clashes between Tigray and Oromo students at Addis Ababa University (AAU) in 2009 which caused injuries on several students; three students were killed and more than forty were injured due to an ethnic-based clash between Amhara and Oromo students at Assosa University in 2017; one student was killed and several injured in Adigrat University on November 2017 due to ethnic-based clash among students; two students killed at Wollega University on December 2017; several injured and blocks of the university put on fire due to clashes between Amhara and Tigray region students at Woldia University on November 2017, and seven were injured due to the clash between Oromo and Southern nation and Nationalities people students at Wachemo University on January 2018.

Some local studies indicated that causes of ethnic conflict are generally related to the ethnic polarization, political rivalry and historical relationship among ethnic groups (Abebaw, 2013a, 2013b) and playing religious songs and holding religious practices like group prayers by some students which create discomfort for the others in dormitories is the cause for religious conflicts among students (Arega \& Mulugeta, 2017). More importantly, it is argued that public universities of Ethiopia do not have clear plan and strategy for managing their students' body diversity and the measures they took to mitigate diversity-related problems such as tension and conflicts are not effective and efficient which needs further investigation (Abebaw, 2014; Abebaw \& Tilahun; 2007; Hailemariam, 2016). Therefore, this study is intended to assess the DM practices and the challenges faced by Ethiopian public universities.

The study was guided by the following basic questions:

- What are the practices of Ethiopian public universities in managing their students' diversity?

- What challenges do the Ethiopian public universities face in managing their students' diversity?

\section{Conceptual framework of the study}

\section{Campus Climate for Diversity}

Campus climate for diversity refers to communities' real or perceived observations of their campus environment as it relates to interpersonal, academic, and professional interactions (Hurtado et al., 2008) or attitudes, perceptions, behaviors, and expectations around issues of race, ethnicity, and diversity (Hurtado et al., 1999; Hurtado, Milem, Clayton-Pedersen, \& Allen, 1998). In other words, it is a framework that provides a way to look at the campus climate to assess how it supports diverse students and whether it creates the type of structures, beliefs, and behaviors that produce the positive effect of diversity on learning for all students (Hurtado et al., 1999). Embedded in the external contexts, government/policy, and sociohistorical, the institutional context of the framework is comprised of institutional-level and individual-level dimensions. According to Milem et al. (2005), while the institutional level dimension includes the institution's historical legacy of inclusion or exclusion; its compositional diversity of students faculty and staff; and organizational structures (institutional policies, curriculum, processes, the individual level of the climate includes the psychological perceptions of individuals, their attitude towards the campus for diversity, and the behavioral dimension that encompasses individual actions and intergroup contact experiences. 
The compositional dimension is also known as structural diversity refers to the numerical representation of individuals from diverse social identities among students, faculty, staff, and administrators (Hurtado et al., 1999). The more balanced representation of a diverse set of individuals within a college or university can lead to greater opportunities for interactions across difference for all (Thompson \& Sekaquaptewa) and is also positively related to satisfaction with the college experience in terms of racial/ethnic diversity as well as ethnic identity development (Hurtado et al., 2012). As can be understood from the concept, structural diversity and changes toward diversification can be counted through enrollment of diverse students. However, according to Hurtado et al. (2008), the perception of the existence of diversity is seen differently by various populations on campus, and for that, the extent of structural diversity of campus should be understood through assessing how diverse the campus feels.

The organizational dimension of the campus climate identifies structures and processes that embed group-based privilege and oppression or confer resources that often go unquestioned, such as curriculum and other institutional practices and policies (Milem et al., 2005). One of the most consistent empirical findings in reviews of many studies is that diversity in the curriculum has the transformative capacity to enlighten and change the perspectives of individuals, especially in the reduction of prejudice (Denson, 2009 as cited in Hurtado et al., 2012; Engberg, 2004; Engberg et al., 2007). Institutional policies and processes can be seen in university policies, programs, and services and have the potential to create more equitable conditions and outcomes for diverse students and can be assessed for equity and diversity (Hurtado et al., 2012). Institutional commitment to diversity, or lack thereof, is also readily identified as an aspect of the organizational dimension of the climate. Such a commitment must be articulated in an institutional mission and maybe well-regarded by students, in particular through transparency and the development of trust (Pepper et al., 2010, as cited in Hurtado et al., 2012). Theory and research on or around the organizational dimension of the climate generally approach the topic from three angles: that of the broader context for institutional policies and practices, specific policies or practices that structure the environment, and processes to improve the climate for diversity on an organizational level (Hurtado et al., 2012).

On the other hand, the first aspect of the individual level dimension of the campus climate for diversity, behavioral dimension, refers to the context, frequency, and quality of interactions on campus between social identity groups and their members (Hurtado, 2005; Hurtado et al., 2008). Categorizing interactions into formal and informal helps educators to understand those interactions they may have control over, as opposed to chance encounters. According to Hurtado (2005), formal interactions are often referred to as campus-facilitated interactions that may occur in the classroom or co-curricular settings and are the result of intentional educational practice and informal interactions that occur in the everyday interactions between individuals outside of campus-designed educational activities. Interaction with faculty is another behavior that is associated with diverse student interactions and impacts student perceptions of the campus climate and subsequent outcomes (Cole, 2007; Cress, 2008 as cited in Hurtado et al., 2012).

Another aspect of the individual level dimension of the campus climate for diversity, the psychological dimension, involves individuals' perceptions of the environment, views of intergroup relations, and perceptions of discrimination or racial/ethnic conflict within the institutional context (Hurtado et al., 1998, 1999); feel somehow singled out because of their background (Nora \& Cabrera, 1996); or perceive institutional support/commitment related to diversity (Hurtado et al., 2008). Climate research based on the psychological dimension remains vital to understanding the experiences of multiple social identity groups to improve the conditions for the success of diverse faculty, students, and staff. For example, researchers like Hurtado et al. (2008) argue that monitoring for the psychological dimension of campus climate is important for higher education administrators as a hostile campus impacts all students negatively and is detrimental to student outcomes, particularly for students of color.

\section{Significances of the Study}

This study will have significance in informing the views of students to public universities about their effort and gap in managing their students' diversity. It will also inform policymakers on the challenges of diversity posing in public universities. For researchers, it can use as reference material and suggest other exploration areas related to diversity.

\section{Definition of Key Terms}

Diversity is a collection of individual attributes (nationality, language, ethnicity, religion, color, race, disability, sexual orientation, age, socio-economic status, and gender) that make all human beings unique and different from each other (Deshwal \& Chaudry, 2012).

Campus Climate for Diversity is a part of the institutional context that includes community members' attitudes, perceptions, behaviors, and expectations around issues of race, ethnicity, and diversity (Hurtado, Milem, Clayton-Pedersen, \& Allen, 1999).

Diversity Management $(\mathrm{DM})$ is the process or strategy of promoting the perception, acknowledgment, and 
implementation of diversity in organizations and institutions (Deshwal \& Chaudry, 2012).

Generation of a university: A conventional classification of Ethiopian public universities based on their year of establishments.

\section{Methodology}

\section{Research Design}

The specific design employed in this study was a convergent parallel mixed method design to collect both forms of data at roughly the same time and then integrates the information in the interpretation of the overall results. Primary data for the study was collected from students, teachers, and dean of students of Ethiopian public universities

\section{Samples and Sampling Techniques}

A combination of different probability and non-probability sampling techniques was used to select an appropriate number of samples. Sample universities were selected using cluster sampling after classifying public universities into four based on their years of establishments usually called 'generational classifications of Ethiopian public universities'. Accordingly, eight universities, two from each of the four generations were selected using simple random sampling. Out of the total of 51,876 students found in the eight sample universities, the number of students to participate in the quantitative study was also determined using a formula suggested by Yamane (1967) to be 398. These participants in the sample public universities were selected using multi-stage sampling; by selecting four colleges from each sample university and using simple random sampling to select the final participants from each college. On the other hand, for the qualitative study, snowball, purposive, and availability sampling techniques were used to select eight participants each from students, teachers, and deans of students that made the total number of participants to be twenty-four.

\section{Data Gathering Tools}

A questionnaire developed by Hurtado et al. (2012) on the Diverse Learning Environment was used in a survey to measure Diverse Learning Environment. The questionnaire had five parts that measure the DM practice of the sample universities with a total of 50 items. The questionnaire was piloted before the actual dissemination for data collection, and the validity and reliability measures were calculated for the whole instrument in general and each dimension specifically. The analysis of the pilot study indicated that the dimensions of the questionnaire have items with good internal consistency as the Cronbach's Alpha Coefficient obtained ranged from 0.73 to 0.91 . The overall Cronbach's Alpha Coefficient was found to be 0.95. On the other hand, in-depth interviews and consultation of documents were the data gathering tools for the qualitative data. In-depth interview guides were used to stimulate discussions and understand participants' views on items on the questionnaire that needed detailed explanation and explore the challenges of Ethiopian public universities in managing their students' diversity. Relevant document reviews were also consulted to add the depth of the quantitative data. To this end, availability, contents, and applicability of documents like or related to strategic plans, senate legislations, and students' code of conduct were reviewed as they are related to the objectives of this study.

\section{Data Analysis}

The data collected through questionnaires were analyzed using the Statistical Package for Social Science (SPSS version 23) to run all basic descriptive and inferential statistics. Descriptive statistics like measures of frequency, percentages, means, standard deviations, and inferential statistics such as independent t-test, and one-way ANOVA were used to analyze the quantitative data. The qualitative data obtained from the in-depth interviews and documents were analyzed using a thematic approach.

\section{Results and Discussions}

To gather the necessary data for the quantitative study, a total of 458 were correctly filled in by students and returned in the study. Out of these students, a little less than half (42.8\%) of them were females while the remaining (57.2\%) were males. Ethnically, 324 (70.7\%) of the students were from Amhara and Oromo ethnic groups. Religion wise, 27.9\% of were Muslims and 52.2\% were Orthodox Christians while the rest were from catholic, protestant, and Wakefeta (traditional) religions. On the other hand, similar to the quantitative participants, $75 \%$ of the student participants were males, and $62.5 \%$ were from Amhara and Oromo ethnic groups. Out of the sixteen teachers who participated in the qualitative study, thirteen hold a second degree and the rest were Ph.D. holders. In terms of academic rank, while eleven of them were assistant professors, the rest five were lecturers. 


\section{Students' diversity management practice in the Ethiopian public Universities}

Table 1. Mean Ratings of Respondents on Diversity Related Policies

\begin{tabular}{lrr}
\hline \multicolumn{1}{c}{ Item } & $\begin{array}{r}\text { Std. } \\
\text { Mean }\end{array}$ & $\begin{array}{c}\text { Deviation } \\
\text { Dhe university's mission specifically refers to the value of having a diversified student body }\end{array}$ \\
$\begin{array}{l}\text { Student code of conduct was distributed for all students when they join this university } \\
\text { Discrimination against any student based on ethnicity is not allowed in this university }\end{array}$ & 3.59 & 3.52 \\
$\begin{array}{l}\text { Discrimination against any student based on religion is not allowed in this university } \\
\text { This University has clear procedures for anyone to report prejudiced or discriminatory } \\
\text { experiences on ethnic and religion issues }\end{array}$ & 3.19 \\
$\begin{array}{l}\text { The university has clear disciplinary procedures to address issues of harassment or } \\
\text { discrimination on ethnic and religion issues }\end{array}$ & 3.25 \\
$\begin{array}{l}\text { The University leadership immediately takes action if a conflict arises due to ethnic or } \\
\text { religion issues }\end{array}$ & 2.94 \\
\hline
\end{tabular}

In the sample universities of this study, as can be noted from table 1 above, respondents reported that there are diversity-related policies in their universities and the policies also contain important issues that can promote diversity. For example, students agree that student code of conduct has been distributed for students when they join their universities $(\mathrm{M}=3.59, \mathrm{SD}=1.16)$ and that the student code of conduct also prohibits discrimination of students based on their ethnicity $(\mathrm{M}=3.52, \mathrm{SD}=1.30)$ and their religion $(\mathrm{M}=3.55, \mathrm{SD}=1.30)$. The study participant students also agree that there are clear procedures in their respective universities for students to report discrimination on ethnic and religious issues $(\mathrm{M}=3.19, \mathrm{SD}=1.28)$ and if they report any form of discrimination or harassment base on their ethnicity or religion, there are clear procedures to address the issues $(\mathrm{M}=3.25, \mathrm{SD}=1.31)$. Despite the existence of the code of conduct to promote diversity, the table also shows that students are not happy about actions taken by the universities' concerned leaders on reported discrimination or harassment of students by their peers or staff $(\mathrm{M}=2.94, \mathrm{SD}=1.42)$.

An attempt was made to understand the inclusion of diversity in the mission statement of the sampled universities through document analysis and interviews with the deans of students. Three of the sample universities had posted their missions, visions, and core values at their campuses in places where it is visible for the university community and anyone visiting the universities. However, there were no indications of having diversity issues included in mission statements. The interviews held with the deans of students also are in agreement with the absence of the issues in the broader sense.

Our university mission statement does not exactly indicate or mention about diversity exactly. But diversity is one of the core values of our university and is included in our strategic plan. (Dean of students, \#2, November 2019)

The strategic plan of the aforementioned university indicates the vision, mission, and core values of the university and section 5.3 of the plan state the following:

Diversity: We must embrace and promote diversity in our policy and practices to prepare our learners and staffs to live and work in an increasingly diverse society (pp. 28);

However, despite the presence of diversity in the sample universities' core values, again the words of the deans of the student in the interview indicate that it was not put in action or the emphasis given for it is minimal. One of the student deans said the following:

We are trying to accommodate diversity in principle not in practice. Let alone student diversity issues, academic staff diversity is not something that we are proud of. Regrettably, in our university case, apart from putting as a core value, we didn't translate it in terms of plans; mean we are doing nothing practically. Had we acted properly, we couldn't face this much problem concerning it (Dean of Students, \#6, February 2020).

Similarly, the data from document review on the availability and contents of policies related to students' diversity management also confirms that student's code of conduct, which is taken from the university's legislation and further developed, are being prepared and distributed for students when they join their universities. With this point one of the deans of students said the following:

When freshman students join our university, there is an orientation session prepared to make them aware of their university and the different rules and regulations of the university. On this occasion, the office of student 
service directorates will make clear what is expected of each student when they live together and distribute student code of conduct for the students (Dean of Students, \#2, November 2109).

Most of the interview participants, similarly, agree that orientation sessions are prepared for freshman students. However, more than half of the participants do not agree that the code of conduct is distributed for newly joining students.

There was an orientation session prepared for us when we joined this university. The main message by then was mainly about the types of departments that we could join, the expected level of performance to pass a semester, and an academic year and to some extent what is expected of us as a university student relates to the rules and regulations of the university. Truth to be told, the university did not distribute the code of conduct for us, or I didn't get the code of conduct (Student, \#6, February 2020).

An attempt was made to gather the student codes of conduct prepared by each sample university and managed to get three approved codes of conduct from three universities. To make the analysis further clear, below are the contents of the codes of conduct of the three universities, Jigjiga, Dire Dawa, and Salale University.

Jigjiga University's students' code of conduct in its forward states that the manual is prepared primarily to teach students the norms of living together in an atmosphere of care and concern for one another rather than to penalize students. The contents of the manual also state that the document contains important information about the consequences of disrespect for others, dishonesty, disobedience of rules and regulations of service giving sections, and offense against the university's justice system, and disciplinary actions and procedures, determination of sanctions, appeal and its proceedings and miscellaneous. Related with the very concern of this study, for example, Article 10 sub-article 1 of the student code of conduct (JJU, 2018) states that:

Verbally abusing, slandering, threatening, or harassing a student intentionally or recklessly will result in a sanction of warning and community service of not less than thirty (30) hours (pp. 16).

Similarly, article 11 with a subtitle of 'Disdaining and mockery of religion, ethnicity, nationality, languages, etc" and having four sub-articles states the following:

(1) Defiling religions of others: This includes but is not limited to abusing, burning and/or defacing holy books, scriptures, religious symbols, preventing the solmization of, or disturbing scoffing at an authorized religious ceremony, or office, profaning a place, image or object used from religious ceremonies will result to expulsion from the university (pp. 20);

(2) Abusing religions, languages, cultures, ethnicity, etc of others verbally or in writing will have a sanction of a suspension from the university for not less than one (1) year (pp. 20);

(3) Offensive comments intent on harming which include but is not limited to ethnic slur, derogatory comments about ethnicity, language, tradition, nationality, religion, etc will result in a sanction of suspension from the university for not less than one (1) year (pp. 20); and

(4) Vandalism or Graffiti that is hate-motivated or conveys an ethnic, religious, linguistic, cultural, etc hatred or otherwise hateful message will result in a sanction of suspension for not less than one (1) year.

Article 87 of the student code of conduct, on the other hand, states how to file a complaint by students.

A complaint should be in writing and submitted as soon as possible after the event has taken place preferably within 7 working days but not more than 30 workdays after the incident have taken place. However, the dean of students or any higher official of the university may launch an investigation into a serious violation of the code of conduct discovered later regardless of when the incident occurred (pp. 104).

Article 89 of the student code of conduct states the composition and jurisdiction of the Student Disciplinary Advisory Committee (SDAC) which is mainly responsible to look over disciplinary problems and put sanctions or recommend the top leadership about the type of action to be taken when the measure to be taken is beyond its jurisdiction. The article was stated as:

The SDAC is a committee that investigates alleged violations of the student code of conduct, which would not normally lead to suspension or expulsion, and imposes sanctions according to the provisions given in the student code of conduct. The committee shall refer to serious violations of the code of conduct that it believes will lead to suspension or expulsion to the student disciplinary Hearing Committee (SDHC). The committee reserves the right to reject a complaint where it feels that the complaint is out of the scope of code of conduct or when it feels that the complaint is trivial (pp. 104-105).

Students' codes of conduct of the three universities suggest that an emphasis was there for students diversity in a way 
that students' are not allowed to discriminate, abuse, or make any physical harm to any other students due to ethnicity or religion. A broader look to the issue in the sample universities also suggests that all the sample universities' senate legislation gave enough emphasis on students' diversity on a separate chapter which they named "Student Affairs". For example, the Senate legislation of Haramaya University on chapter nine Article 151 put the following:

151.5. Students admitted into the University are expected to act honorably based on integrity, common sense, and respect for the law of the land and public morality at all times, both on and off-campus settings. They assume an obligation to behave in a manner compatible with the University's function as an educational institution (pp. 218).

151.8. When, however, a student abuses his academic freedom he may be subject to disciplinary actions in accordance with the Student Code of Conduct institution (pp. 219).

In general, the results from both the quantitative and qualitative data above indicate that the sample universities have policies and plans that can address diversity-related issues of their students though their implementation is not given much attention. This may be due to the lack of concern given by the university's top administrators. Norris (2000) and Tarasco (2012) state that no plan can be implemented successfully without the strong support and commitment of higher officials of an institution.

\section{Perception Difference of Respondents on Diversity related Policies}

Table 2. Independent Sample t-test of Respondents Regarding Diversity related Policies

\begin{tabular}{ccccccccc}
\hline & \multicolumn{3}{c}{ Group Statistics } & \multicolumn{3}{c}{ Independent sample T-test } \\
\hline & Sex & $\mathrm{N}$ & Mean & $\begin{array}{c}\text { Std. } \\
\text { Deviation }\end{array}$ & $\begin{array}{c}\text { Std. Error } \\
\text { Mean }\end{array}$ & $\mathrm{t}$ & $\mathrm{df}$ & $\begin{array}{c}\text { Sig. } \\
(2-\text {-tailed })\end{array}$ \\
\hline $\begin{array}{c}\text { Diversity related } \\
\text { Policies }\end{array}$ & Female & 196 & 3.3914 & .81648 & .05832 & -.115 & 456 & .908 \\
& Male & 262 & 3.4008 & .89074 & .05503 & & &
\end{tabular}

As can be seen from Table 2 above, no significant mean difference between the sample population was observed $(\mathrm{p}=0.908)$. This implies that there was no significant perception difference between male and female students about the availability and implementation of diversity-related policies.

Similarly, no significant perception difference was observed by students of different ethnic groups on diversity-related policies $(\mathrm{F}(3,454)=0.600, \mathrm{p}=0.615)$, religion $(\mathrm{F}(3,454)=0.728, \mathrm{p}=0.536)$, and generation of universities $(\mathrm{F}(3,454)$ $=2.070, \mathrm{p}=0.103$ ).

\section{Top University Leadership Commitment to Promote Students' Diversity}

As can be noted from table 3 below, students strongly agree that a welcome ceremony/an orientation session was organized for freshman students when they join their university $(\mathrm{M}=3.91, \mathrm{SD}=1.23)$. The university leadership also emphasizes the value of having ethnically $(\mathrm{M}=3.37, \mathrm{SD}=1.27)$ and religion $(\mathrm{M}=3.21, \mathrm{SD}=1.25)$ diverse student body when they meet their students on different occasions or meetings.

Table 3. Mean Ratings on the University's Top Leadership Commitment to Promote Students' Diversity

\begin{tabular}{lcc}
\hline \multicolumn{1}{c}{ Item } & Mean & $\begin{array}{c}\text { Std. } \\
\text { Deviation }\end{array}$ \\
\hline $\begin{array}{l}\text { A welcome ceremony or orientation session was organized for first-year students when they } \\
\text { join the university }\end{array}$ & 3.91 & 1.23 \\
$\begin{array}{l}\text { The University Leadership emphasizes the value of having ethnically diverse ethnic student } \\
\text { body on different occasions or meetings }\end{array}$ & 3.37 & 1.27 \\
$\begin{array}{l}\text { The University Leadership emphasizes the value of having a diverse religion student body } \\
\text { on different occasions/meetings }\end{array}$ & 3.21 & 1.25 \\
$\begin{array}{l}\text { The University Leadership is committed to creating a campus environment that welcomes all } \\
\text { students of different ethnic background }\end{array}$ & 3.36 & 1.25 \\
$\begin{array}{l}\text { The University Leadership is committed to creating a campus environment that welcomes all } \\
\text { students of different religion background }\end{array}$ & 3.29 & 1.29 \\
$\begin{array}{l}\text { The University Leadership promotes the understanding of Ethnic differences } \\
\text { The University Leadership promotes the understanding of religion differences }\end{array}$ & 3.20 & 1.31 \\
\hline
\end{tabular}


As data in table 3 above indicates, the university leadership is committed to creating a campus environment that welcomes students from different ethnicities $(M=3.36, S D=1.25)$ and religious background $(M=3.29, S D=1.29)$. Moreover, the students' response also shows that they agree with the fact that their university leadership is promoting the understanding of ethnic $(\mathrm{M}=3.20, \mathrm{SD}=1.31)$ and religious $(\mathrm{M}=3.09, \mathrm{SD}=1.29)$ differences to create an understanding between students.

An attempt was also made to substantiate the findings of the quantitative data with qualitative data from students and deans of students through interviews. For example, though students and deans of students have different understandings about the messages passed during the freshman welcome ceremony or an orientation session, as was mentioned previously (See section 4.2.3), they agree with the fact of the presence of the mentioned program. As to the word of one of the students:

A year before last year, when I first joined this university, there was an orientation session organized for the freshman students in which I took part. I can't deny the fact that there were some messages about what is expected of students when living together on the campus. But most of the focus was on academic issues like a minimum requirement to pass as a semester, the number of the department in each college, and awarding best achieving senior students in general and female students, in particular, to motivate us in our upcoming study. I do not think that the issue of diversity was given much focus though there was high tension at public universities of conflict between students for diversity issues mainly ethnicity. (Student, \#6, February 2020)

A dean of students from the same university also agrees with the presence of the session and believes that the messages passed about diversity and tolerance is enough as a starting message which could be further developed after students get used to their campuses:

In our university case, time is allotted for student service directorates to briefly discuss the student code of conduct which informs them to leave harmoniously and refrain from wrongdoings. Taking the length of the program, I think it is enough though I think that there should be other sessions on this issue. (Dean of Students, \#5, November 2019)

On the other, though the quantitative results show that, university leaders' effort in promoting diversity and bringing tolerance among different ethnic and religious background students is appreciated, the qualitative results from students and student deans do not agree with that. Both students and deans of students claim that university leaders meet their students during holidays and some circumstances like serious conflict not regularly in a planned manner. For example, one student interview participant said the following:

Our University leaders are personally sociable and easy to approach. They try to discuss different issues with the whole student body in general and student union members in particular if there are serious instances like conflicts. (Dean of Students, \#3, December 2019)

Similarly, a dean of students from one of the sampled universities supports the above claim made by the student:

Unless it is a holyday or serious conflict incident, the university top leaders do not intentionally gather students and discuss with students different issues including diversity. I know they have very frequent contact with student union members. Even with student union members, I doubt that the issue of is diversity is their main concern. (Dean of Students, \#4, December 2019)

Another point of disagreement of the quantitative and qualitative data is on the issue of the commitment of the top leadership in creating tolerance among different ethnic and religious groups of students. As the qualitative findings are mainly informed, there are no formal sessions between the universities' top leaders and students to discuss the issue of student diversity. If that is the case, then their effort to create harmony and tolerance among students is highly doubtable. One case though is undeniable; their effort to discuss the issues of diversity even after compelling instances like conflicts.

\section{Perception Difference among Respondents on Leadership Commitment towards Diversity}

An attempt was made to see if there is a difference in perception between respondents on leadership commitment towards diversity. 
Table 4. Independent Sample t-test regarding Leadership Commitment

\begin{tabular}{ccccccccc}
\hline \multicolumn{3}{c}{ Group Statistics } & & \multicolumn{3}{c}{ Independent sample T-test } \\
\hline & Sex & N & Mean & $\begin{array}{c}\text { Std. } \\
\text { Deviation }\end{array}$ & $\begin{array}{c}\text { Std. Error } \\
\text { Mean }\end{array}$ & t & df & $\begin{array}{c}\text { Sig. } \\
\text { (2-tailed) }\end{array}$ \\
\hline $\begin{array}{c}\text { Leadership } \\
\text { commitment to } \\
\text { Diversity }\end{array}$ & Female & 196 & 3.3980 & .88176 & .06298 & .955 & 456 & .340 \\
& Male & 262 & 3.3108 & 1.02475 & .06331 & & &
\end{tabular}

As can be seen from Table 4 above, the result from the t-test implied that no significant mean difference was observed between male and female students on leadership commitment towards diversity $(\mathrm{p}=0.379)$. As a result of the ANOVA test, a significant perception difference in leadership commitment towards diversity was observed across a generation of universities, $F(3,454)=6.034, \mathrm{p}=0.000)$. The result of the post hoc analysis revealed that differences exist between the second and third generation of universities and second and fourth generation of universities. Thus, the null hypothesis, H 1.20, was not supported. On the other hand, there was no significant difference observed about leadership commitment towards diversity among students of different ethnicity $F(3,454)=0.725, \mathrm{p}=0.537)$ and religion $F(3,454)$ $=2.011, \mathrm{p}=0.112$ ).

\section{Co-curricular practices related to Students' Diversity in Universities}

As can be seen from Table 5 below, students agree $(\mathrm{M}=3.45, \mathrm{SD}=1.30)$ that life skill sessions that acknowledge and promote diversity of students have been prepared for students when joining their university. On the other hand, respondents of the quantitative study moderately agree on their participation in a session whereby guest speakers from different ethnic groups give a lecture on ethnic $(\mathrm{M}=3.17, \mathrm{SD}=1.29)$ and religious $(\mathrm{M}=2.99$, $\mathrm{SD}=1.25)$ diversity awareness.

Table 5. Mean Ratings of Respondents on Practice of Co-Curricular Activities to Promote Students' Diversity (N=458)

\begin{tabular}{lrr}
\hline Items & Mean & SD \\
\hline $\begin{array}{l}\text { I had attended the life skill training that contained issues of ethnicity and religion when I } \\
\text { first joined this university }\end{array}$ & 1.30 \\
At this University, I had attended themed events and activities organized to promote & 3.44 & 1.23 \\
understanding of students from different backgrounds & & \\
I had attended a session whereby guest speakers from different ethnic groups gave a lecture & 3.17 & 1.29 \\
on ethnic diversity awareness & & \\
I had attended a session whereby guest speakers from different religious groups gave a & 2.99 & 1.25 \\
lecture on religion diversity awareness & 3.04 & 1.27 \\
I had participated in ethnic/cultural festivals organized by this university & 2.99 & 1.22 \\
I had attended to watch performance organized by students on ethnic and religion issues & 3.12 & 1.31 \\
At this University, some associations and clubs appeal to students' varied interests & 2.90 & 1.26 \\
I am participating in club activities & 3.09 & 1.30 \\
Students from different ethnic backgrounds hold positions at the students union & 3.00 & 1.36 \\
Students from different religious and backgrounds hold positions at the students union & 3.00
\end{tabular}

As can also be inferred from data in the table above, students' participation in ethnic or cultural festivals organized by their university is moderate $(\mathrm{M}=3.04, \mathrm{SD}=1.27)$. Again, though study participants agree on the presence of different clubs that appeal to students' varied interest $(\mathrm{M}=, 3.12 \mathrm{SD}=1.31)$, their participation in the clubs is minimal $(\mathrm{M}=2.90$, $\mathrm{SD}=1.26$ ). Regarding the composition of the student union in their university, students have a moderate perception that students from different ethnicities $(\mathrm{M}=3.09, \mathrm{SD}=1.30)$ and religion $(\mathrm{M}=3.00, \mathrm{SD}=1.36)$ background hold different positions. In general, the application of different co-curricular activities by the sample universities to manage students' diversity was rated as moderate.

The qualitative data obtained from students and deans of students on this aspect of diversity management also shows an agreement with the result of the quantitative study. For example, a student participant had said the following on the presence and contents of the life skill training organized by his university and attended by his and his colleagues assigned to the university three years ago:

There was a life skill training session that lasted for two days. Informative topics were discussed including 
how to live with friends from different cultures and how to live in the campus peacefully while attaining the main objective of being here, learning. I think that training was very helpful most students to help themselves better know the general knowledge of campus life. (Student, \#5, November 2019)

Most of the deans of students also agree that the session is very helpful and very crucial for students to equip them psychologically to college life waiting for them ahead.

The life skill training session is prepared by the guidance and counseling directorate and most of the trainers are from the department of psychology. Though that is given, as far as the information that I have on the session is concerned, the training helps full for students to pre equip them about the type of life that awaits them, advise them on how to be successful in their training and equip them psychologically to be strong to enjoy their life in campus. Therefore, in a way to discuss the importance of peaceful co-existence on campuses, the different discussions will also be raised about diversity and respecting differences including but not limited to differences in ethnicity and religion. (Dean of Students, \#5, November 2019)

Similar to that of the life skill sessions, the quantitative data showed that there were different sessions whereby guest speakers from different ethnic and religious backgrounds were invited and made a discussion with students to raise awareness about the importance of having a diversified student body, on campuses in particular, and for the country in general. The qualitative data obtained also, in most cases, supported this finding even though the difference in the aim of the session is sometimes found to be different. For example, two deans of students said the following:

We invited many peace activists, intellectuals from the region, and even famous artists to make a speech for our students about peace, difference, and the beauty of our diversity. I can mention some of them. Obang Metho, the Gambella peace activist known for his motto of "Humanity First, Somali professors who thought and served in high positions abroad and here in this country and artists like Solomon came to our university and discussed with our students the issue of diversity and peace. The sessions were very interesting and very informative. I have a feeling that the relative peace that we had in these turbulent periods of conflicts in many of the other public universities goes to the implication of these. As I had told you, since we have A diversity Directorate in this university, every one of the sessions was planned. (Dean of Students, \#2, November 2019)

Though it is not frequent, we had invited local leaders including religious leaders from different religions to discuss the issue of peace with students once this year. I also remember there was also one guest speaker from abroad last year. In general, truth to be told, though it is not much organized and frequent, the effort is there. (Dean of Students, \#3, December 2019)

On the other hand, however, another dean of students witnessed the absence of such sessions in his university. His words were:

I certainly believe that such sessions have paramount importance to promote diversity. Unfortunately, as to my best knowledge, I didn't participate in such sessions which were planned and organized by the university. As I am the student service director, if there was a plan, I think, it was supposed to be the plan of my office. But, I cannot deny the fact that aba Gedas, the local community elders, and religious leaders do participate in welcoming our students at the beginning of the year and even participate in the freshman welcoming ceremony. (Dean of Students, \#1, November 2019)

As was argued in the background and literature session, these types of sessions have to be well planned and targeted to raise the perception of students on diversity issues and should not necessarily be done when there are some issues of diversity including conflicts between students for diversity issues. But in most cases, the platforms were thereafter conflicts were raised between different ethnic groups of students to settle down students who wanted to leave their campus in a group. Again here one of the deans of students said:

Honestly speaking, we didn't do much on this issue by having a plan. But, after the very terrible and regrettable conflict, we had between Amhara and Oromo students which coasted us the precious lives of two of our students, some students wanted to leave the campus claiming that they don't feel safe here because of what happened and their ethnicity, we invited local and religious leaders to talk to students and it helped us a lot. Personally, though I always felt the importance of such platforms, after that incident, I had a strong initiation to have these sessions regularly in the future. (Dean of Students, \#4, December 2019).

Another dean of students also added that:

The sessions were not as planned before the violent conflict between students that cost the lives of two of our students, many injured, 27 of them expelled, and our university to be officially closed for more than three weeks because of the conflict. Even after that conflict, many students wanted to leave the campus and were convinced to stay with the effort of the local community and religious leaders. After that, we had prominent 
professors, other guests and religious leaders talk about peace, diversity, and federalism. (Dean of Students, \#6, February 2020)

Just like that of the deans of students, students also witnessed the same on the issue. For example one of the interview students said:

I didn't know such session's before this years' conflict between Amhara and Oromo students. But after the university was reopened, some guests mainly community and religious leaders were invited to talk to us about peace. It is working, I think. In general, the university's effort regarding this is very poor. I don't know whether you're the people of this city, they are very sociable, peaceful and very generous. They don't care about your ethnicity or religion. If you approach them, they will treat you as a family and they are known for this behavior of them throughout the country. They are the huge resources that our university failed to use to create peace (Student, \#6, February 2020).

Other co-curricular activities that better help to acknowledge and promote student diversity is the involvement of students in different cultural and other festivals meant to strengthen the students' unity and coexistence. The Ethiopian public universities previous trend indicated these festivals include sports festival, different cultural ceremonies, "Irrecha" (thanksgiving festival of the Oromo ethnic group mainly celebrated at the beginning of a new year), the celebration of Nations and Nationalities day, the day the current constitution of the country was enacted, December 6/7 each year and many more others. The qualitative results held with both students and deans of students, however, show that the celebration of such festivals is weakened and even in some cases banned by university leaders as the platforms are becoming sources of conflicts for students. As to the word one of the student:

Every year there is a football competition, which we call it as GC (graduating students) cup, between different departments of graduating class students. I am a graduating class student but since it was banned by the university officials starting from last year claiming that students are going to conflict for simple issues, I had no chance to enjoy that competition and it is very sad. The same is true for the case of nations and nationalities day. We didn't celebrate it this year as our campus was not peaceful by then. Truth to be told, it was also banned two years before (Student, \#4, December 2019).

In a way to share the opinion of the above student, a student dean also said with a very sad tone:

We used to have a sports competition, mainly football, among different batches of students to strengthen their unity. Also, the Nations and Nationalities day celebrations were so colorful that every student eagerly wanted to celebrate by preparing foods and wearing clothes of different cultural and ethnic groups. In our campus even, there is a roundabout in front of the main gate named as Nations and Nationalities square. But these days as they became a source for conflicts, the university administration banned the celebration of such festivals. .... Students may say that the music from my ethnic group was not played and may simply disturb the event and may go to conflict with others. In football competitions, you don't know when and how students go to conflicts. You think that they are from different batches but you may see conflicts between students based on ethnicity. It is very sand, and that is the reason for the university to ban such competitions and festivals. (Dean of Students, \#3, December 2019).

In general, sports competitions, religious and cultural festivals, and other events that bind students and create a sense of unity are being diminished from time to time.

Another finding of the qualitative study regarding co-curricular activities pertains to the involvement of students in club activities and student union, an association which is legally recognized by the senate legislation of all the sample universities and responsible to be the voice of the student community. For example, Chapter 30, Article 272 and sub article1 of the senate legislation of Dire Dawa university (Dire Dawa, 2019, p. 242) states:

As students constitute a vital component of the University community, they shall be provided with the means and forums for enhancing self-government and democratic participation in the affairs of the university, particularly by forming student organizations promoting academic pursuits and their personal development.

Concerning the student organization, the same legislation in its article 273 sub-article 6 states the following:

The Director of Students' Services Affairs shall devise a mechanism for the organization of the Student Union in a manner conducive for democratic representation of students and inclusive of all student interest groups (p. 243).

In line with the legislation provisions, an attempt was made to explore the presence of varied clubs that students can participate in and more importantly the presence and representation of diverse background students in the student union, the main association of students. Concerning the involvement of students in clubs, in agreement with the quantitative findings, except for two of the students' interview participants, the rest had no formal involvement in clubs. Asked on 
the main reasons for her failure to participate in club activities, one student said the following:

I had no such experience when I was at elementary and secondary schools. Besides, after I joined this university, I found the study to be time taking and stressful. So I thought that participating in clubs would consume my time and for that, I had no involvement in such activities. (Student, \#5, November 2019)

Concerning clubs and associations that work mainly on diversity issues, another student interviewee explained:

In our university, apart from many clubs, we do have a peace forum and student union that work directly about the wellbeing of the student community. It is known that, even by legislation, the student union is an association of students responsible for every matter concerning students and participate in the student discipline committee and has representation in the senate. On the other hand, peace forum, being responsible directly for the president of the university, is responsible to work on issues related to peace including creating awareness about peace, making a discussion with students on different issues including diversity issues, and solving minor incidents between students before it grows to major conflict. (Dean of Students, \#2, November 2019)

Though these two student associations are very critical to promote students' diversity, interview participants also could not hide the fact that there are some issues in representations of different students in such associations, mainly student union and the peace forum. According to one of the student deans:

One of our findings of the overall performance of the student service directorate after the conflict that made us close our university was related to the student union and peace forum associations. We had learned that, instead of settling down students during the conflict, student peace forum members were mainly involved in the conflict by siding their ethnic group of students. Also, when we examine the ethnic composition of both student union and peace forum, we had found that it was highly dominated by one ethnic group. Therefore, after the re-opening of our university, we had dismantled both associations and replaced them with new members. Many students were not happy about both associations and it makes sense. (Dean of Students, \#6, February 2020)

\section{Perception Difference among Respondents on Diversity related co-curricular activities}

Table 6. Independent Sample t-test Regarding Diversity related Co-curricular Activities

\begin{tabular}{ccccccccc}
\hline \multicolumn{3}{c}{ Group Statistics } & \multicolumn{3}{c}{ Independent sample T-test } \\
\hline & Sex & $\mathrm{N}$ & Mean & $\begin{array}{c}\text { Std. } \\
\text { Deviation }\end{array}$ & $\begin{array}{c}\text { Std. Error } \\
\text { Mean }\end{array}$ & $\mathrm{t}$ & $\mathrm{df}$ & $\begin{array}{c}\text { Sig. } \\
(2 \text {-tailed) }\end{array}$ \\
\hline $\begin{array}{c}\text { Diversity } \\
\text { related } \\
\begin{array}{c}\text { Co-curricular } \\
\text { Activity }\end{array}\end{array}$ & Female & 196 & 3.0684 & 3.1485 & .87755 & .06268 & .636 & .456 \\
& Male & 262 & 3.0053 & 3.0954 & .88749 & .05483 & & \\
\hline
\end{tabular}

As can be seen from Table 6 above, the t-test result showed that no significant mean difference between the sample population was observed $(\mathrm{p}=0.456)$. This implies that there was no significant perception difference between male and female students' attitudes towards diversity. Thus the null hypothesis, H 1.21, was supported.

The result from the one way ANOVA also revealed that no significant perception difference regarding diversity-related co-curricular activities was observed by students of different ethnic groups $F(3,454)=0.453, \mathrm{p}=0.715)$, religion $F(3$, 454) $=0.311, \mathrm{p}=0.817)$, and generation of universities $F(3,454)=1.661, \mathrm{p}=0.175)$. Thus, all the three the null hypotheses, $\mathrm{H} 1.22, \mathrm{H} 1.23$, and $\mathrm{H} 1.24$ were supported.

\section{Curricular Practices related to Students' Diversity in the Universities}

Table 7 below presents the responses of students about the curricular practices concerning diversity in their respective universities. As can be noted from the table, students' take on the curricular practice related to diversity is relatively low with an overall mean rating of 2.76. For example, the respondents disagree that they had taken courses that have reading on religion $(\mathrm{M}=2.87, \mathrm{SD}=1.33)$ issues which allowed them to make a dialogue with students of different religions $(\mathrm{M}=2.86, \mathrm{SD}=1.28)$ backgrounds. This shows that the curriculum is insufficient in creating an exposure either to read diversity issues, mainly religion or to make a dialog with other students of different religious backgrounds in a way to explore the cultures and principles of other religions. Though the clear disagreement, according to the results, is related to religious issues, the case of ethnic issues is also not satisfactory as the mean ratings are very close to the cut point, 3.0. Similarly, the respondents disagree that their university library has a wide variety of materials on ethnicity $(\mathrm{M}=2.74$, $\mathrm{SD}=1.30)$ and religious $(\mathrm{M}=2.55, \mathrm{SD}=1.25)$ issues. The lack of these reading materials, apart from the exclusion of diversity contents in the curriculum will make the effort of the students to know and explore diversity inefficient. 
Table 7. Mean Ratings of Respondents on Practice of Curricular Activities to Promote Students' Diversity (N=458)

\begin{tabular}{lll}
\hline Item & Mean & SD \\
\hline In this university, I have taken courses that have a reading on ethnic issues & 3.16 & 1.34 \\
In this university, I have taken courses that have a reading on religious issues & 2.87 & 1.33 \\
In this university, I had taken courses that allowed me to make a dialogue with students of & 3.01 & 1.30 \\
different ethnic background & & 1.28 \\
In this university, I had taken courses that allowed me to make a dialogue with students of & 2.86 & 1.30 \\
different religion background & 2.74 & 1.30 \\
The university library has a wide variety of materials on ethnicity issues & 2.55 & 1.25 \\
The university library has a wide variety of materials on religion issues & 3.53 & 1.29 \\
In classes, teachers' pay the same amount of attention to all students regardless of their & 3.46 & 1.30 \\
ethnicity & 2.53 & 1.31 \\
In classes, teachers' pay the same amount of attention to all students regardless of their religion & 3.48 & 1.30 \\
In classes, teachers treat students more negatively if they are not from their ethnicity & 3.34 & 1.24 \\
In classes, teachers treat students more negatively if they are not from their religion & 3.21 & 1.29 \\
In classes, teachers instruct us on good ways to communicate across ethnicity & 2.87 & 1.29 \\
In classes, teachers instruct us on good ways to communicate across religion & \\
In classes, teachers make students aware of the harm of stereotyping other students based on & \\
their ethnicity & 2.91 & 1.33 \\
In classes, teachers make students aware of the harm of stereotyping other students based on & 3.52 & 1.23 \\
their religion & 3.26 & 1.25 \\
In classes, teachers encourage students to express different views and perspectives & 3.26 & 1.31 \\
In classes, teachers encourage students to challenge popular ideas & 3.60 & 1.26 \\
When assigning groups, teachers place students with different ethnic and religious backgrounds & & \\
together & &
\end{tabular}

Another practice with the curricular activities that were assessed in this study pertains to the behavior of teachers about giving attention to their students, equal treatment irrespective of the students' background, ethnicity, and religion. In this regard, respondents of the quantitative study agree that teachers are fair in giving attention and treating students irrespective of their ethnicity $(\mathrm{M}=3.53, \mathrm{SD}=1.29)$ and religious $(\mathrm{M}=3.46, \mathrm{SD}=1.30)$ backgrounds. Very specifically, respondents strongly agree that students are positively treated by a teacher irrespective of their ethnicity $(\mathrm{M}=2.53$, $\mathrm{SD}=1.31)$ or religion $(\mathrm{M}=2.48, \mathrm{SD}=1.30)$.

Teachers' behavior related to the encouragement of students to participate and make communication across different backgrounds was also assessed by the quantitative respondents. For example, teachers' effort in encouraging students' to participate in discussions and ask questions $(\mathrm{M}=3.60, \mathrm{SD}=1.26)$, to communicate across ethnicity $(\mathrm{M}=3.34, \mathrm{SD}=1.24)$, and $(\mathrm{M}=3.21, \mathrm{SD}=1.29)$, religion, express different views and perspectives $(\mathrm{M}=3.52, \mathrm{SD}=1.23)$, challenge most popular ideas $(\mathrm{M}=3.26, \mathrm{SD}=1.25)$, and form groups by placing different students from different ethnicities and religions $(\mathrm{M}=3.26, \mathrm{SD}=1.31)$ is in positive agreement by the quantitative respondents. As the literature suggests, these kinds of efforts by teachers highly contribute to promoting diversity, create a very good relationship between students, and explore different languages and cultures. On the other hand, however, student participants of the quantitative study disagree that the effort of teachers to make students aware of the harm of stereotyping other students based on their ethnicity $(\mathrm{M}=2.87, \mathrm{SD}=1.29)$ and religion $(\mathrm{M}=2.91, \mathrm{SD}=1.33)$. In instances where students from different backgrounds are being assigned in the same dormitory to live together and students go to conflict for ethnic and religious issues, the lack of such commitment from teachers may pose a challenge in diversity promotion in public universities.

The qualitative results about the treatment of students by their instructors in academic matters show an agreement with quantitative findings through the qualitative data suggests that there are incidents whereby some teachers do not follow their professional ethics. For example, the following was said by one of the students:

Student \# 1: ... most of my teachers are very ethical and do not make differential treatment of students if they are not either from their ethnic or religious group. This doesn't mean that all are the same. I remember, for example, that most of my batch students were having a complaint on the communicative English instructor who thought us when we were freshman students. I mean, we tried our best by studying to score a good grade, but the final result was not up to our expectations. Very surprisingly, we finally noticed that students who came from some area were having an excellent grade despite the fact they were also poor in the subject. 
Probe: How did you know that they are poor in that subject matter?

Student \#1: Some of them used to live with us in the same dormitory and somehow study the subject together. Apart from that, some of their performances in the class, like speaking practice, were not different from us if not poor comparatively. Also, after the final grade when we claim regarding our department, they said it will not be possible though they were also convinced that our claim is true. But after I joined this department, I can say that such differential treatment is almost none, as to my best knowledge. (Student, \#1, November 2019)

Almost similar to the above student, one instructor also said on professional ethics of teachers in his department:

As I am the department head for almost the last two years, it gave me to look at this issue very closely. Generally, the treatment of our academic staff to our students is very good. This doesn't mean that there are no cases of complaints by students about very few teachers about differential treatment, especially with grading. Truth be told, we found some of the complaints to be true. (Teacher, \#2, November 2019)

The same instructor complains that:

... sometimes when students find their courses very difficult and score lower grades, they also come to the department to accuse the instructor claiming that the teacher illegally punished them or reduced their grades because of their ethnicity or some gender issues. I mean, it is the order of the day to relate anything and everything with ethnicity. They think that they can win the case if they precede it this way. We take such cases very seriously and do a check following the procedure and put the party responsible for discipline. (Teacher, \#1, November 2019)

In any case, the much-appreciated effort of teachers to be ethical in treating their students irrespective of their background, ethnicity or religion, is an encouraging practice that can hugely contribute to diversity promotion, as such behaviors of teachers will put students in comfort and create a good relationship between the two. One critical problem worth mentioning here also is the diversity composition of instructors at public universities. As the qualitative findings also suggest, most instructors of the sample universities came from the region where the university is located, mainly from the same local area. For example one of the teachers said the following on this issue which is supported almost by the rest of the qualitative respond teachers and students too:

It is facts that in the last four years after the ethnic-based conflict in the country gets very worse and many displaced from their home and made to leave, much academic staff also left their universities in the same way. For example, after the conflict between Somali and Oromo people in this region, man Oromo teachers left our university, formally or informally. For that case, if you go to some universities, because of the mass presence of this university's academic staff, they are being called as branches of our university. What is very sad above all is that the number of Oromo and Amhara teachers in our university used to be very good, but now it is very low and I can feel that that is not good and even it may not give comfort for students from these ethnic groups and direct every of the complaint in line with this issue. (Teacher, \#2, November 2019)

The inclusion of diversity issues in the curriculum of undergraduate programs in Ethiopian public universities was also a point of discussion in the interview with students and teachers. Though students have a huge interest to know about the history, culture, and uniqueness of ethnic groups other than theirs specifically and the history of Ethiopia in general, they suggest that the curriculum is not giving them such a chance. Except for some department students, for example, history, sociology, psychology, anthropology, and sociology, many of the students in other departments indicated that they did not take the course that helps them to enquire about diversity except the course known as Civic and Ethical Education which they used to take it beginning from junior school level, the second cycle of elementary education, to be exactly as per the structure of the Ethiopian Education system before the suggestion of new road map. As to the response of some teachers, even in the above departments, the curriculum content of the issue of diversity for students of a highly diverse country like Ethiopia is not satisfactory. In his words one teacher commented the following:

I do not think that the curriculum is exposing the students of higher education at the level required especially for students of colleges of engineering, natural and computational college, and business and economics. It doesn't mean that all students of the college of social science, however, have better exposure. If you take for example, in our department, psychology, there is a very interesting course that I took at the undergraduate level, but no more in the curriculum nowadays, cross-cultural psychology. I think the issue of such courses in general of the question of the academicians of the country for long. The courses vanished when the freshman program was made to disappear by the governments' decision. I think starting from this year, courses on diversity that will enable us to know about different cultures and religions are being introduced at the freshman level which is very encouraging and may bring students understanding of each other by exposing to different discussions inside the class. It is very interesting and important. (Teacher, \#2, November 2019) 
Capitalizing on the importance of such courses, one student also said the following about the curriculum's responsiveness to diversity issues:

... what we understood from the overall situation of the country is that history and ethnicity are at the conflict between Ethiopian society. For that, at least, higher education students should know the basic history of our country and multiculturalism to be problem solvers in the future. But from the way I see it, I didn't have enough lessons that I took with this except the course of civic and ethical education which I know from elementary school. Even if you take that course, its content was better at the high school level as it deals with the Ethiopian context mostly, which the university one is lacking. Honestly speaking, as I was very eager to know about different cultures and the history of Ethiopia, I am very sad to graduate without having enough knowledge in these areas. At the very least, there were no field trips, even a single one, in which I had to explore the culture of one ethnic or local group. Everything focuses on your professional area. Though it is good from a quality perspective, I think as a higher education graduate, we need some knowhow on history and multiculturalism too. (Student, \#6, February 2020)

The Ethiopian Education Development Road Map (MoE, 2018), also states

Ethiopia, after the adoption of the constitution in 1995, has endorsed the federal system, which recognizes unity in diversity. Nations, Nationalities, and Peoples were exercising their political, cultural, and language rights. However, while universities have exercised to promote diversity, none of the Ethiopian universities have activities to promote unity (pp.51).

Interestingly, in agreement with the comments by students and teachers of the qualitative participants, the document also recommends the following:

Introduce new courses to make students get exposure to the diverse culture/peoples of Ethiopia. Introducing a multicultural course including Geography and Anthropology courses that focus on Ethiopia may help students to focus on unity within diversity, and

The education policy should encourage universities to promote co-curricular and extra-curricular activities that help students to be involved in different clubs that fit their inclination so that they can interact with people different from them. The

the government needs to allocation earmarked budget for these activities and designate office that would coordinate such activities (pp. 52)

Another practice explored concerning curricular practices of sample universities is students' group formation behavior inside classrooms and the attention given by teachers to make the group diversified so that students of different backgrounds can interact, know each other, and get engaged academically and socially inside and outside the classroom. Regarding the issue a student in an interview said the following:

If given the chance, I think students want to organize themselves mainly taking mother tongue language or ethnicity and the area where they came from into consideration. This is very evident from the fact students sit inside the class that way. Unfortunately, most of the time, teachers and the department assign group members for classroom discussion and group assignment based on academic performance to make students help each other. (Student, \#2, November 2019)

Asked the same question during an interview, teachers also aid similar to the students about the preference of students in organizing themselves for group formation and the practice they are following. As to the word of one teacher:

... no question, if we allow them to form a group by themselves, the criteria to be considered will be language and ethnicity in most cases. Some may go for friendship or being in the same dormitory, very possibly. In reality, a group is made by the subject teacher in a way to help low performing students to get help from academically better students. Truth to be told, I also consider background mix as I am a sociologist and always wanted my students of different backgrounds to interact. That may create a strong relationship between students as they have to meet to do group projects and assignments frequently. That way they may share language and culture main importantly know each other better and stand for each other at times of conflict or other circumstances. Because this is the way we live and we are living as Ethiopians. (Teacher, \#4, December 2019)

The quantitative study showed that students disagree that instructors advise their students about the harm of stereotyping others based on their background. Though most of the teachers said that most teachers were trying to calm down students during conflicts, they also stated that some teachers were also on the opposite side. Taking this as a starting point, they also said that some teachers may not be engaged in advising their students about stereotyping because of their background. One teacher said the following: 
I think most of our staff are very ethical and do advise their students about the issue. But this doesn't mean that there are no teachers who were found out of their ethics. For example, sadly, we had found some teachers behind the recent conflicts let alone give a piece of advice for their students on the harm of stereotyping. These teachers used to wear black clothes to pass a message that they also are with the student as students were also wearing black cloths to imply that they are in grief because of the loss of their ethnic group students at other public universities. (Teacher, \#6, February 2020)

\section{Perception Difference between Respondents on Diversity related curricular activities}

Table 8. Independent Sample t-test regarding Diversity related Curricular Activities

\begin{tabular}{ccccccccc}
\hline & \multicolumn{3}{c}{ Group Statistics } & & \multicolumn{3}{c}{ Independent sample t-test } \\
\hline & Sex & $\mathrm{N}$ & Mean & $\begin{array}{c}\text { Std. } \\
\text { Deviation }\end{array}$ & $\begin{array}{c}\text { Std. Error } \\
\text { Mean }\end{array}$ & t & $\begin{array}{c}\text { Sig. } \\
\text { df }\end{array}$ & (2-tailed) \\
\hline $\begin{array}{c}\text { Diversity } \\
\text { related } \\
\begin{array}{c}\text { Curricular } \\
\text { Activities }\end{array}\end{array}$ & Female & 196 & 3.0684 & .66890 & .04778 & .940 & 456 & .348 \\
& Male & 262 & 3.0053 & .73866 & .04563 & & &
\end{tabular}

As can be seen from Table 8 above, the t-test result showed that no significant mean difference between the sample respondents was observed $(\mathrm{p}=0.348)$. This implies that there was no significant perception difference between male and female students about the attitude towards diversity.

As was also observed from the ANOVA result, no significant perception difference regarding diversity-related curricular activities was observed between students of different ethnic groups $(\mathrm{F}(3,454)=0.917, \mathrm{p}=0.433)$, religion $(\mathrm{F}(3,454)$ $=0.116, \mathrm{p}=0.951)$, and generation of universities $(\mathrm{F}(3,454)=0.380, \mathrm{p}=0.767)$.

\section{Challenges in Managing Students' Diversity in the Public Universities}

As the interview results indicated, the challenges the public universities faced to manage their students' diversity can be divided into two: internal and external challenges. The internal challenges included lack of attention given for the issue by the universities leadership, service provision related to cafeteria services, ethnic homogeneity of universities top leadership, the dominance of students and staffs from local areas, and political issues run by students and teachers. On the other hand, the external challenges mentioned by interview participants included the overall political situation of the country, activists focus on university students, and the placement criteria of the Ministry of Education.

It was argued earlier that most universities did not include the issue of students' diversity in their mission which implies a lack of commitment towards the issue. Even in cases whereby some indicated diversity issues in their strategic plan, they failed to translate it to work plans and work on the issue. However, as to writers in the field like Hurtad et al. (2008), in countries like Ethiopia whereby ethnic and religious diversity are markers of the country, higher education institutes should have a lot of concern to bring the best out of their students' diversity. The diversity promotion can take the form, as to the respondents, the inclusion of the issue in annual plans which can be implemented, preparation of different panels and forums with known personalities and local and religious leaders to create more awareness of the issue by students, and establishing different units and clubs that work diversity issue. The response of one dean of students asserts the instance of top leaders' commitment towards diversity. He said:

Unless there are instances of conflict or some serious matters, top leaders do not meet with students. Again, though we had stated that students' diversity to be one of our concern in our strategic plan, you don't see much commitment from the university in doing so which can be witnessed from lack of specific strategies, well-planned panels and forums on diversity, and weak commitment to enforcing what is put on students discipline guideline. For example, after incidents of conflicts between students, we invited community elders and religious leaders to talk with students and that brought a very good result. It means that if we had done it regularly before incidents of conflicts, which could be a very good strategy to promote students' diversity. (Dean of students, \#4, December 2019)

Higher education institutes in Ethiopia are perceived as secular institutes, free from ethnic and religious interferences. With this, the Ministry of Education prepared a guideline for students which state about worship, dress code, and food etiquette in higher education institutes (MoE, 2011). The guideline states what is and is not allowed to religious issues. Among issues that are not allowed to be practiced include the preparation of foods that are similar to all students of all religious groups. However, in reality, this is not the case. As argued by students and deans of students, foods for Christians and Muslims are prepared and served in different compartments during fasting periods of Orthodox Christians and in days whereby the food contains meat as an ingredient. In addition to that, as some of the deans of 
students explained, during fasting periods of orthodox Christians and Muslims, cafeterias are opened after the normal service time to serve fasting students.

Though we do not assign workers to serve the students like the regular service period, we open the cafeteria for fasting periods [for both Christians and Muslims] so that they can serve themselves after they fast for the day is over. This is usually at 2:30 PM for Orthodox Christians and near to 7 PM for Muslims. (Dean of students, \#5, November 2019)

If universities refuse to serve fasting students in a special circumstance as indicated earlier, the issue can be a point of conflict between the students and the university administration. The special arrangement also creates dissatisfaction for other students, for Christians in the case of Muslims fasting period and vice versa, and will be an issue during other periods. Students' interview participants also indicate that there is a special favor made for students of the same religion with that of the administration. Most deans of students perceive this practice as against the secular education policy of higher education institutes and can also widen religious differences of students which will result in student segregation in terms of religion for other in-campus activities.

Another issue stated by respondents as a challenge to manage students' diversity is a homogeneity of the academic staff and university leadership in terms of ethnicity in most cases and religion in some instances. Because of the political and administrative system at the national level, there seems to be a growing tendency of teachers towards working in one's region. For example, according to Abebaw and Tilahun (2007) and Tilahun (2010), there is a tendency for teachers from other regions to leave the University and for teachers from the region where the University is geographically located to come to the University, and this decreases teacher diversity. In the same token, it is customary to see the top university leadership to be from the same ethnic group, in most cases. When students see teachers and top leaders from their ethnic or religious group, they feel a sense of belongingness towards their university. When this is not the case, students feel dissatisfied by their university and look for a transfer to another university, mostly to the region where they came from. This will, in turn, decreases the structural diversity of students and may create dominance of other ethnic groups.

As I was telling you earlier, due to a conflict between Oromo and Somali students, many Oromo students and teachers left our university [Jigjiga University]. That hugely affected the ethnic composition of our students. Not only that, again as I stated earlier, but Oromo students who are being assigned to our university after that incident also are not feeling comfortable not to see many Oromo teachers and students on the campus. Observing this situation, I and my colleague are assigned to serve here, Student Service Directorate, since we speak Afan Oromo just to make them feel better. (Dean of Students, \#2, November 2019)

I consider universities not only national but also universal. If you take, for example, the case of most public universities in our country, it is usual to find Indians professors almost everywhere. Sadly, on the contrary, public universities are stacked with Ethiopian teachers from the locality of the university, take our university for example. Of course, it is advantageous for the teachers as the current political scenario of the country forces you to do that to be secured. On the other hand, it is very challenging for the university and students coming from other regions. Students who came from other regions would not feel this much discomfort had the teachers mix [ethnically] was reasonable. I even think that the extreme polarization of ethnicity is mainly related to this case. (Teacher, \#4, December 2019)

The recently increasing political activities of students and instructors inside campuses were also mentioned as a challenge to manage students' diversity in the sample universities. According to teachers and student respondents, students usually bring a political agenda to the campus and informally organize students from their ethnic group, mainly, to promote it. It was also noted that the same agendas are being pushed by teachers and even administrative staff members. Sadly, most of the agendas were ethnic issues that resulted in conflicts between students of different ethnic groups.

In recent conflicts between students [Amhara and Oromo], our assessment showed that there were students who intentionally ignited it. Sadly and very surprisingly, their agenda was also supported by teachers and administrative staff which made the control very difficult. For example, during peace talks, we observed teachers wearing black cloths [to indicate grief] to indicate they are with students. How can other students expect fair treatment in class from those teachers? Do you think that they feel comfortable here? I don't think. (Dean of Students, \#1, October 2019)

As argued by interview respondents also, fake news, activists, and other politicians focus on university students to initiate conflicts between students, and the overall political situation of the country is mentioned as external factors that made students' diversity management challenging for public universities. All students' participants in the interview agree on the fact that fake news disseminated through social media like Facebook was one contributing factor for students not to stand together irrespective of their ethnicity on certain issues which resulted in conflicts. The students claim that most of the fake news was related to ethnic issues that segregate students based on their ethnic identity. One 
student said:

As we know very well, almost all university students are on Facebook and there is much fake news circulating on different social media including Facebook. Surprisingly, most of the fake news is related to ethnic issues and students accept it as true even without cross-checking it with other sources. These fake news always preach that one ethnic group of students are being oppressed in a certain university by another ethnic group which will then create a sense of hate between students of different ethnic groups in other universities. Then taking that news, you will see that students of a different ethnic group of students seeing each other as enemies on the campus, and whenever they find it suitable, they even go to conflicts with simple issues. (Student 6 , February 2020)

Concerning the fake news, the students and dean of students mention that the messages of different activists and political groups for public university students were also another issue that made the students' diversity management challenging for public universities. The respondents mentioned that the recent political change in the country had resulted in known political activists and partied/groups in different ethnic groups which are very much respected and their words heard. The challenging aspect of this trend is that peoples including public university students take their words without questioning even if it will result in conflict between students which may claim their lives. Remembering such circumstances, an interviewee student said:

There are activists of different ethnic groups which, I can say that is worshiped by peoples including students. Sadly, these activists or political groups pass a message through social media that creates a sense of being an enemy among students. I do not think that they really care about students' lives, they simply pass their message and the result is going to be very ugly. Taking their words, I heard students saying "I do not want to learn together with students of such and such ethnicity". (Student, \#7, February 2020).

Of course, both the students and the dean of students claim that all the challenges are related to the current political instance of the country. After the recent political crisis in the country, it was customary to hear conflict between different ethnic groups of peoples which resulted in mass execution and killings. The participants agree that these instances at the country level had impacted students' relationships inside campuses which makes students' diversity management challenging.

\section{Conclusions and Implications}

Based on the findings of the study, it was concluded that the students' diversity management practice of Ethiopian public universities is moderately good and the deficiency of the curriculum to respond to diversity-related issues, and lack of commitment of university leaders to promote diversity and act immediately during conflicts was mentioned as gaps in managing students' diversity. Finally, it was recommended that due attention should be given by MoSHE and respective public universities in diversifying the top leadership, academic staff, and student body by putting appropriate strategies in place.

\section{References}

Abebaw, A. (2013a). Intergroup relations among ethnically diverse university students in Ethiopia. Journal of Education and Research, 3(2), 77-95. https://doi.org/10.3126/jer.v3i2.8399

Abebaw, A. (2013b). Causes of ethnic tension and conflict among university students in Ethiopia. ATINER'S Conference Paper Series, No: EDU2013-0644, Athens.

Abebaw, A. (2014). Ethnic and religious diversity in higher education in Ethiopia: The case of Bahirdar University (Unpublished Ph.D. Dissertation). University of Tampere, Finland.

Abebaw, A., \& Tilahun, B. (2007). Higher education institutions as pavilions of diversity: Opportunities and challenges: The case of Bahirdar university. Ethiopian Journal of Higher Education, 4(1), 49-68.

Aigare, A., Thomas, L., \& Koyumdzhieva, T. (2011). Diversity management in higher education institutions (Unpublished Doctoral Dissertation). Jönköping University.

Ambissa, K. (2010). Education and diversity: pupils' perceptions of 'others' and curricular responses at selected sites in Ethiopia. The Ethiopian Journal of Education, 30(1), 23-50.

Antonio, A. L. (2001). Diversity and the influence of friendship groups in college. The Review of Higher Education, 25(1), 63-89. https://doi.org/10.1353/rhe.2001.0013

Arega, B., \& Mulugeta, N. (2017). Interpersonal conflicts and styles of managing conflicts among Students at Bahirdar University, Ethiopia. Journal of Student Affairs in Africa, 5(1), 27-39. https://doi.org/10.24085/jsaa.v5i1.2480

Banks, J. A. (2001). Cultural diversity and education: Foundations, curriculum, and teaching (4th ed.). Boston: Allyn 
\& Bacon.

Barbosa, I., \& Cabral-Cardoso, C. (2007). Managing diversity in academic organizations: A challenge to organizational culture. Women in Management Review, 22(4), 274-288. https://doi.org/10.1108/09649420710754237

Bell, L. A., \& Griffin, P. (1997). Designing social justice education courses. In M. Adams, L. A. Bell, \& P. Griffin (Eds.), Teaching for diversity and social justice: A sourcebook (pp. 44-58). New York: Routledge.

Bennett, C. I. (1999). Comprehensive multicultural education: Theory and practice (4 ${ }^{\text {th }}$ ed.). Boston: Allyn $\&$ Bacon.

Brown, L. I. (2004). Diversity: The challenge for higher education. Race Ethnicity and Education, 7(1), 21-34. https://doi.org/10.1080/1361332042000187289

Dawson, M. (2007). Identity formation among learners at a South African high school: Assessing the interaction between context and identity. Race, Ethnicity, and Education, 10(4), 457-472. https://doi.org/10.1080/13613320701658472

Deshwal, P., \& Chaudry, S. (2012). Workforce diversity management: The biggest challenge for $21^{\text {st }}$-century managers. IOSR Journal of Business and Management, 16(4), 102-107. https://doi.org/10.9790/487X-1643102107

Dobbin, F. (2009): Inventing equal opportunity. Princeton, N.J.: Princeton University. https://doi.org/10.1515/9781400830893

Engberg, M. E. (2004). Improving intergroup relations in higher education: A critical examination of the influence of educational interventions on racial bias. Review of Educational Research, 7(4), 473-524. https://doi.org/10.3102/00346543074004473

Engberg, M. E., \& Hurtado, S. (2011). Developing pluralistic skills and dispositions in college: Examining racial/ethnic group differences. Journal of Higher Education, 82(4), 416-443. https://doi.org/10.1080/00221546.2011.11777211

Engberg, M. E., Hurtado, S., \& Smith, G. C. (2007). Developing attitudes of acceptance toward lesbian, gay, and bisexual peers: Enlightenment, contact, and the college experience. Journal of Gay \& Lesbian Issues in Education, 4(3), 49-77. https://doi.org/10.1300/J367v04n03_05

FDRE. (2019). Higher Education Proclamation No, 650/2009. Negarit Gazeta, Addis Ababa.

Figueroa, P. (1999). Multiculturalism and anti-racism in a new era: a critical review. Race, Ethnicity and Education, 2(2), 281-302. https://doi.org/10.1080/1361332990020207

Gurin, P., Dey, E., Hurtado, S., \& Gurin, G. (2002). Diversity and higher education: Theory and impact on student outcomes. Harvard Educational Review, 72(3), 330-367. https://doi.org/10.17763/haer.72.3.01151786u134n051

Hailemariam, K. (2016). Diversity Management and students' Cross Border Learning Experiences at Selected Ethiopian Universities (Unpublished Dissertation Proposal). University of South Africa (UNISA).

Haileyesus, T. (2010). Ethnic identity and interethnic relations among Addis Ababa University's main campus freshman students (Unpublished MA thesis). Addis Ababa University, Addis Ababa.

Hurtado, S. (2005). The next generation of diversity and intergroup relations research. Journal of Social Issues, 61, 595-610. https://doi.org/10.1111/j.1540-4560.2005.00422.x

Hurtado, S. (2007). Linking diversity with the educational and civic missions of higher education. The Review of Higher Education, 30(2), 185-196. https://doi.org/10.1353/rhe.2006.0070

Hurtado, S., \& Guillermo-Wann, C. (2013). Diverse Learning Environments: Assessing and Creating Conditions for Student Success - Final Report to the Ford Foundation. University of California, Los Angeles: Higher Education Research Institute. https://doi.org/10.1007/978-94-007-2950-6_2

Hurtado, S., Alvarez, C., Guillermo-Wann, C., Cuellar, M., \& Arellano, L. (2012). A Model for diverse learning Environments: The scholarship on creating and assessing conditions for student success. A book chapter on Higher Education: Handbook of theory and research. Springer Science and business media. https://doi.org/10.1007/978-94-007-2950-6_2

Hurtado, S., Griffin, K., Arellano, L., \& Cuellar, M. (2008). Assessing the value of climate assessments: Progress and future directions. Journal of Diversity in Higher Education, 4(1), 204-221. https://doi.org/10.1037/a0014009

Hurtado, S., Matthew, J., \& Mark, E. (2003). Diversity in the classroom and Student's Moral Reasoning. Paper prepared for the Association for the study of higher education, Portland, OR: November 12-16, 2003.

Hurtado, S., Milem, J., Clayton-Pedersen, A., \& Allen, W. (1998). Enhancing campus climates for racial/ethnic diversity: Educational policy and practice. The Review of Higher Education, 21(3), $279-302$. 
https://doi.org/10.1353/rhe.1998.0003

Hurtado, S., Milem, J., Clayton-Pedersen, A., \& Allen, W. (1999). Enacting diverse learning environments: Improving the climate for racial/ethnic diversity in higher education. ASHE-ERIC Higher Education Report, 26(8), 5-127.

Jaeger, P., \& Reverdy, S. (2013). Diversity climate assessment survey results and analysis. University of Mary Land, USA.

Jayakumar, U. M. (2007). Can higher education meet the needs of an increasingly diverse society and global marketplace? Campus diversity and cross-cultural workforce competencies. Unpublished doctoral dissertation, University of California, Los Angeles. https://doi.org/10.17763/haer.78.4.b60031p350276699

Klarsfeld, A. (2010). International handbook on diversity management at work: Country perspectives on diversity and equal treatment. Cheltenham, Edward Elgar.

Locks, A., Hurtado, S., Bowman, N., \& Oseguera, L (2008). Extending notions of campus climate and diversity to students' transition to college. The Review of Higher Education, 31(3), 257-285. https://doi.org/10.1353/rhe.2008.0011

Lumadi, M. (2008). Managing diversity at higher education and training institutes: A daunting task. Journal of Diversity Management, 3(4), 1-10. https://doi.org/10.19030/jdm.v3i4.4996

Metcalfe, B.D. (2010). Diversity, management, and leadership development. Gower Handbook of Leadership and Management Development (5th Edn). England: Gower Publishing.

Milem, J. F., Chang, M. J., \& Antonio, A. L. (2005). Making diversity work on campus: A research-based perspective. Washington: American Association of Colleges and Universities.

MoE. (2002). The guideline for implementing student placement in public universities. Addis Ababa.

Onsman, A. (2010). Cross-border teaching and the globalization of higher education: problems of funding, curriculum quality, and international accreditation. Lewiston: The Edwin Mellen Press.

Pillay, V. (2010). Diverging on diversity and difference: The mask of inclusion. Journal of Perspectives in Education, 28(3), 13-22.

Pitts, D., \& Jarry, E. (2007). Ethnic diversity and organizational performance: Assessing diversity. International Public Management Journal, 10(2), 233-254. https://doi.org/10.1080/10967490701323738

Sharabi, M. (2011). Culture, religion, ethnicity, and the meaning of work: Jews and Muslims in the Israeli context. Culture and Religion, 12(3), 219-235. https://doi.org/10.1080/14755610.2011.605157

Skelly, M. E. A. (2004). Campus climate and diversity issues: Listening to students. (Unpublished doctoral dissertation). Montana State University, Montana.

Teddlie, C., \& Tashakkori, A. (2009). Foundations of mixed methods research: Integrating quantitative and qualitative approaches in the social and behavioral sciences. Thousand Oaks CA: Sage.

Teshome, G. (2001). Conflict of ethnic identity and the language of education policy in contemporary Ethiopia. International Conference on African Development Archives. Paper 31.

Umbach, P., \& Kuh, G. (2006). Student experiences with diversity at liberal arts colleges: Another claim for distinctiveness. The Journal of Higher Education, 77(1), 169-192. https://doi.org/10.1080/00221546.2006.11778923

Vermeulen, P. (2011). Diversity management in higher education: A South African perspective in comparison to a homogeneous and Monomorphous society such as Germany. Working paper No. 43. Center for Higher Education Development.

Worthington, R. (2013). Comprehensive campus climate study for diversity and inclusion of western Michigan University. WMU, USA.

\section{Copyrights}

Copyright for this article is retained by the author(s), with first publication rights granted to the journal.

This is an open-access article distributed under the terms and conditions of the Creative Commons Attribution license which permits unrestricted use, distribution, and reproduction in any medium, provided the original work is properly cited. 